\title{
A METHOD TO ESTIMATE OPEN PACK-ICE THICKNESS FROM TWO-DAY SEQUENCES OF SIDE-LAPPING SATELLITE IMAGES
}

\author{
by
}

\author{
Uri Feldman
}

(Department of Geography, Bar-Ilan University, Ramat Gan 52100, Israel)

\begin{abstract}
A method to estimate open pack ice thickness drifting in a marginal ice zone (MIZ) is presented. The estimates are obtained from two-day sequences of sidelapping Landsat-1 MSS images and two-day sequences of wind field data by four steps: estimating the surface wind speed, estimating the angle of sea ice deflection, estimating three ratios between ice parameters and estimating the lower and upper limits of pack ice thickness. The method has been applied to six groups of open pack ice floes drifting in the MIZ of the Beaufort Sea during 1973-1975. In the absence of simultaneous in-situ observation, the results have not been tested. The method presented may be applied to any MIZ. Rather than using Landsat-1 MSS images, data from a high resolution active microwave remote sensing system should be employed in the future as its data will be independent of sun illumination and cloud cover.
\end{abstract}

\section{INTRODUCTION}

A knowledge of pack ice thickness is vital for studying pack ice dynamics (Hibler 1979) and its impact on the environment (Weller and others 1983). Since in situ or remotely sensed measurements of pack ice thickness are not routinely available for the polar oceans, a method to estimate thickness of open pack ice floes, drifting in a marginal ice zone (MIZ), is suggested. The estimates are obtained by solving a reduced form of the general equation of motion for drifting pack ice, using data from four readily available sources. The estimates are obtained by four steps:

a. Estimating the surface wind speed.

b. Estimating the angle of sea ice deflection.

c. Estimating three ratios between ice parameters.

d. Estimating the lower and upper limits of pack ice thickness.

The method has been applied to six groups of open pack ice floes drifting in the MIZ of the Beaufort Sea during 1973-75.

\section{ESTIMATING OPEN PACK ICE THICKNESS}

The general equation of motion for drifting pack ice (Campbell 1965) may be reduced to a simple steady state equation of motion if applied to weekly drifts of open pack ice, since impact of ocean currents on pack ice drifting in the Beaufort Sea is negligible for weekly drifts (Feldman and others 1981). In this equation, wind stress, water drag and the horizontal Coriolis force per unit area of ice are assumed to be at equilibrium. If a Cartesian coordinate system, in which $+\mathrm{x}$ is chosen to be the direction of ice motion, is employed then wind stress is always positive, $-x$ is direction of water drag and $-y$ is direction of the Coriolis stress. The $\mathrm{x}$ and $\mathrm{y}$ components of this equation are written as:

$$
\rho_{\mathrm{a}} \mathrm{C}_{\mathrm{d}}^{\mathrm{a}} \mathrm{U}^{2} \cos \Delta_{\mathrm{y}}=\rho_{\mathrm{w}} \mathrm{C}_{\mathrm{d}}^{\mathrm{w}} \mathrm{V}^{2}
$$

and

$$
\rho_{\mathrm{a}} \mathrm{C}_{\mathrm{d}}^{\mathrm{a}} \mathrm{U}^{2} \sin \Delta_{\mathrm{y}}=\rho_{\text {ice }} 2 \omega \sin \phi \mathrm{hV}
$$

where $\rho_{\mathrm{a}}$ is air density, $\mathrm{C}^{\mathrm{a}}$ is drag coefficient at the air/ice interface, $\mathrm{U}$ is horizontal wind speed at $10 \mathrm{~m}$ above the ice surface, $\Delta_{y}$ is the angle of sea ice deflection, $\rho_{w}(=1.03$ $10^{3} \mathrm{~kg} \mathrm{~m}^{-5}$ ) is ocean water density, $\mathrm{C}_{\mathrm{d}}^{\mathrm{W}}$ is drag coefficient at the water/ice interface, $V$ is speed of center of gravity of a group of open pack ice floes, $\rho_{\text {ice }}\left(=0.9110^{3}\right.$ $\left.\mathrm{kg} \mathrm{m}^{-3}\right)$ is ice density, $\omega\left(=7.29210^{-5} \mathrm{~s}^{-1}\right)$ is Earth's angular speed of motion, $\phi$ is latitude and $h$ is mean thickness of a group of open pack ice floes.

Position of ice floes has been measured from 1: 1000 Landsat-1 MSS images, by a Ruscom digitizer, using control points located on land. Assuming linear motion for the floes, during a two-day sequence, accuracy of positional measurements is $\pm 100 \mathrm{~m}$. Hence, errors in position may vary between \pm 0.25 and $5 \%$ relatively to the motion of the center of gravity of a group of ice floes. Location of ice floes drifting away from land may be determined by means of space triangulation. Errors of ice velocity are identical to errors in position, since temporal data are highly accurate.

Means of $\phi$ in Equation (2) have been determined for groups of drifting open pack ice from Landsat-1 MSS images. $V$ in equations (1) and (2) has been derived for the intermediate scanning time $t_{11 i+1}\left(=t_{12}, t_{23}, t_{34}\right)$ from twoday sequences of sidelapping Landsat-1 MSS images, scanned at $t_{i}$ and $t_{i+1}$ respectively. $\rho_{a}$ in equations (1) and (2) has been derived and time adjusted to $t_{11 \mathrm{i}+1}$ by means of linear interpolation from two-day sequences of six-hour surface weather charts. Estimates of $U$ in Equations (1) and (2) have been obtained for $t_{11 i+1}$ from the geostrophic wind speed $G$ by the formula of Feldman and others (1979). Values of $G$ have been derived and time adjusted to $\mathrm{t}_{11 \mathrm{i}+1}$ by means of linear interpolation from two-day sequences of six-hour. surface weather charts. Estimates of $\Delta y$ in equations (1) and (2) have been obtained for $t_{11 \mathrm{i}+1}$ following the work of Feldman and others (1981). The variables $h, C_{d}^{\mathrm{a}}$ and $\mathrm{C}_{\mathrm{d}}^{\mathrm{W}}$ cannot be derived from the available data. Hence, they must be estimated.

To determine the ratios $\mathrm{M}, \mathrm{N}$ and $\mathrm{B}$, Equation (2) has been rewritten as

$$
\mathrm{M}=\mathrm{h} / \mathrm{C}_{\mathrm{d}}^{\mathrm{a}}=\left(\rho_{\mathrm{a}} \mathrm{U}^{2} \sin \Delta_{\mathrm{y}}\right) /\left(\rho_{\text {ice }} 2 \omega \sin \phi \mathrm{V}\right)
$$

Equation (1) has been written as

$$
\mathrm{N}=\mathrm{C}_{\mathrm{d}}{ }^{\mathrm{w}} / \mathrm{C}_{\mathrm{d}}{ }^{\mathrm{a}}=\left(\rho_{\mathrm{a}} \mathrm{U}^{2} \cos \Delta_{\mathrm{y}}\right) /\left(\rho_{\mathrm{w}} \mathrm{V}^{2}\right)
$$


TABLE I. EXTREME VALUES OF $h, \mathrm{C}_{\mathrm{d}}^{\mathrm{a}}$ AND $\mathrm{C}_{\mathrm{d}}^{\mathrm{w}}$

\begin{tabular}{llr} 
Variable & Min. & Max. \\
\hline $\mathrm{h}$ & 0.00 & 3.00 \\
$10^{3} \mathrm{C}_{\mathrm{d}}{ }^{\mathrm{a}}$ & 0.95 & 4.00 \\
$10^{3} \mathrm{C}_{\mathrm{d}}{ }^{\mathrm{w}}$ & 3.32 & 57.17 \\
\hline
\end{tabular}

TABLE II. ICE THICKNESS ESTIMATED FROM TWO-DAY SEQUENCES OF LANDSAT-1 IMAGES

\begin{tabular}{ccccccc} 
Data & LS-1 & UT & Date & $\mathrm{h}_{\mathrm{LL}}$ & $\mathrm{h}_{\mathrm{UL}}$ & $\overline{\mathrm{h}}$ \\
Set & Cycle & & & $\mathrm{m}$ & $\mathrm{m}$ & $\mathrm{m}$ \\
\hline
\end{tabular}

\begin{tabular}{lllllll}
1.1 & 21 & $0810: 25$ & July 25,1973 & 1.81 & 3.00 & 2.43 \\
1.2 & 21 & $0816: 10$ & July 26, 1973 & 2.64 & 2.96 & 2.80 \\
2.1 & $26 \mathrm{a}$ & 0814.50 & Oct. 24,1973 & 3.09 & 2.36 & 2.73 \\
2.2 & $26 \mathrm{a}$ & $0820: 20$ & Oct. 25, 1973 & 2.93 & 2.83 & 2.88 \\
\hline 2.3 & $26 \mathrm{a}$ & $0826: 05$ & Oct. 26, 1973 & 2.22 & 3.00 & 2.61 \\
\hline 3.1 & $26 \mathrm{~b}$ & $0827: 30$ & Oct. 26, 1973 & 3.62 & 2.07 & 2.84 \\
3.2 & $26 \mathrm{~b}$ & $0832: 15$ & Oct. 27, 1973 & 2.14 & 3.00 & 2.59 \\
3.3 & $26 \mathrm{~b}$ & $0837: 50$ & Oct. 28, 1973 & 1.81 & 3.00 & 2.40 \\
4.1 & 41 & $0831: 20$ & July 25, 1974 & 4.08 & 2.05 & 3.06 \\
4.2 & 41 & $0837: 00$ & July 26, 1974 & 1.80 & 3.00 & 2.40 \\
4.3 & 41 & $0842: 40$ & July 27, 1974 & 2.07 & 3.00 & 2.53 \\
\hline 5.1 & 43 & $0801: 25$ & Aug. 25, 1974 & 5.00 & 3.00 & 4.00 \\
\hline 5.2 & 43 & $0807: 10$ & Aug. 26, 1974 & 7.14 & 3.00 & 5.07 \\
6.1 & 60 & $0737: 00$ & June 25, 1975 & 1.81 & 3.00 & 2.41 \\
6.2. & 60 & $0742: 35$ & June 26, 1975 & 2.31 & 3.00 & 2.66 \\
\hline
\end{tabular}

and $\mathrm{B}$, defined from (3) and (4), has been written as

$$
\mathrm{B}=\mathrm{h} / \mathrm{C}_{\mathrm{d}}{ }^{\mathrm{w}}=\mathrm{M} / \mathrm{N}
$$

The observed minimum and maximum of $\mathrm{h}, \mathrm{C}_{\mathrm{d}}{ }^{\mathrm{a}}$ and $\mathrm{C}_{\mathrm{d}}{ }^{\mathrm{w}}$, (Table I), summarized by Feldman and others (1981) from previous observations, have then been employed to rewrite Equation (5) as

$$
\mathrm{h}=\mathrm{C}_{\mathrm{d}}{ }^{\mathrm{w}} \mathrm{B} \geqslant 3.3210^{-3} \mathrm{~B} \mathrm{~m}
$$

Equation (3) as

$$
\mathrm{h}=\mathrm{C}_{\mathrm{d}}^{\mathrm{a}} \mathrm{M} \geqslant 0.9510^{-3} \mathrm{M} \mathrm{m}
$$

and $\mathrm{h}$ as

$$
h=h \geqslant 0.00 \mathrm{~m}
$$

This allows Equations (6), (7) and (8) to be rewritten as

$$
\mathrm{h} \geqslant \max \left\{3.3210^{-3} \mathrm{~B}, 0.9510^{-3} \mathrm{M}, 0.00\right\}=\mathrm{h}_{\mathrm{LL}} \mathrm{m}
$$

where $h_{L L}$, the lower limit of $h$, is the maximum value among the three values in Equation (9). In the same way, $\mathrm{h}_{\mathrm{UL}}$, the upper limit of $\mathrm{h}$, is the minimum value among the three values in Equation (10)

$\mathrm{h} \leqslant \min \left\{57.1710^{-3} \mathrm{~B}, 4.0010^{-3} \mathrm{M}, 3.00\right\}=\mathrm{h}_{\mathrm{UL}} \mathrm{m}$

$\mathrm{B}$ and $\mathrm{M}$, which are employed to estimate $\mathrm{h}$ in Equations (9) and (10), are linearly related to $\mathrm{V}$ in Equations (3) and (5). Hence, errors in $\mathrm{V}$ will linearly affect $\mathrm{B}$ and $\mathrm{M}$.

The method has been applied to six groups of open pack ice floes, drifting in the MIZ of the Beaufort Sea. The lower limit, upper limit and mean thickness estimated by the method for the six groups are presented in Table II.

\section{CONCLUSIONS}

An estimate of open pack ice thickness is considered unacceptable if its lower limit is larger than its upper limit $\left(\mathrm{h}_{\mathrm{LL}}>\mathrm{h}_{\mathrm{UL}}\right)$. 
In the absence of simultaneous in situ observations of pack ice thickness, accuracy of the results cannot be tested.

The method may be applied to estimate thickness of open pack ice drifting in any MIZ, by using two-day sequences of sidelapping images.

The required wind field data should be obtained directly from weather data banks rather than from surface weather charts.

Rather than using Landsat-1 MSS images, data from a high resolution active microwave remote sensing system should be employed in the future, as its data will be independent of sun illumination and cloud cover.

\section{REFERENCES}

Campbell W J 1965 The wind-driven circulation of ice and water in a polar ocean. Journal of Geophysical Research 70(14): $3279-3301$

Feldman U, Howarth P J, Davies J A 1979 Estimating the surface wind speed over drifting pack ice from surface weather charts. Boundary Layer Meteorology 16(4): 421-429

Feldman U, Howarth P J, Davies J A 1981 Estimating surface wind direction over drifting open pack ice. Journal of Geophysical Research 86(C9): 8117-8120

Hibler W D III 1979 A dynamic thermodynamic sea ice model. Journal of Physical Oceanography 9(4): 815-846

Weller G, Carsey F, Holt B, Rothrock D A, Weeks W F 1983 Science program for an imaging radar receiving station in Alaska. Report of the Science Working Group. Pasadena, CA, NASA Jet Propulsion Laboratory 